\title{
Análisis de procedimientos autorreferenciales en algunas producciones teatrales de Luis Palacio a partir del estudio del material significante escénico.
}

\author{
Mario Alberto Palasi \\ CONICET-UNSL-UNC \\ albertopalasi@gmail.com \\ Artículo bajo licencia Creative Commons \\ Atribución 4.0 Internacional (CC BY 4.0) \\ ENVIADO: 2021-04-27 \\ ACEPTADO: 2021-10-19
}

\section{RESUMEN}

Las tensiones entre ficción y realidad en la escena se producen a partir del desplazamiento de los materiales significantes de los creadores desde su propio deseo. Desde el análisis de estos materiales en movimiento, tanto en el texto dramático como en la escena, en los cuadernos de bitácora y en las entrevistas con los creadores, utilizando como herramienta metodológica los vectores deseantes (Pavis, 2000), observamos que no sólo son procesos autorreferenciales los géneros docudramas, autoperformances, autoficciones y biodramas, sino que todo espectáculo, ficcional o no, tiene una carga autorreferencial relacionada con las segmentaciones de territorialización, des-territorialización y reterritorialización.

Estos procedimientos de autorreferencialidad fueron estudiados en las producciones de Luis Palacio, dramaturgo, director y actor de la provincia de San Luis, Argentina.

\section{RESUMO}

As tensões entre ficção e realidade em cena são produzidas a partir do deslocamento dos materiais significantes dos criadores de seu próprio desejo. A partir da análise desses materiais em movimento, tanto no texto dramático quanto na cena, nos diários de bordo e nas entrevistas com os criadores, utilizando os vetores desejantes como ferramenta metodológica (Pavis, 2000), observamos que eles não são apenas processos autorreferenciais gêneros docudramas, auto-performances, autoficções e biodramas, mas todo espetáculo, ficcional ou não, tem uma carga autorreferencial relacionada à segmentação da territorialização, desterritorialização e reterritorialização.

Esses procedimentos

autorreferenciais foram estudados nas produções de Luis Palacio, dramaturgo, diretor e ator na província de San Luis, Argentina.

\section{ABSTRACT}

The tensions between fiction and reality in the scene are produced from the displacement of the significant materials of the creators from their own desire. From the analysis of these moving materials, both in the dramatic text and in the scene, in the logbooks and in the interviews with the creators, using the desiring vectors as a methodological tool (Pavis, 2000), we observe that they are not only self-referential processes the docu-drama genre, self-performances, self-ictions and biodramas, but every show, fictional or not, has a self-referential burden related to the segmentations of territorialization, deterritorialization and re-territorialization.

These self-referential procedures were studied in the productions of Luis Palacio, playwright, director and actor in the province of San Luis, Argentina.
PALABRAS CLAVE

Teatro, autorreferencialidad, territorialidad, significantes, vectores deseantes.
PALAVRAS-CHAVE

Teatro, autorreferencialidade, territorialidade, significantes, vetores desejantes.

\section{KEYWORDS}

Theater, self-referentiality, territoriality, signifiers, desiring vectors. 


\section{Formación y poÉtica de LUIS Palacio}

Luis Palacio comienza sus primeras experiencias teatrales a fines de la década del 90 en la ciudad de Villa Mercedes de la provincia de San Luis, Argentina, y es en la década siguiente cuando sus producciones adquieren notoriedad dentro y fuera de San Luis. Con amplia formación en montaje teatral junto a maestros como Jorge de Lazzaletta y Rubén Szuchmacher, seminarios de dirección y actuación teatral con Jorge Díaz, Pompeyo Audivert, Alexander Barynin y de dramaturgia con Susana Lage, Paco Sarzozo, Mauricio Katún y Alejandro Zingman, entre otros realiza importantes producciones como actor, director y dramaturgo. Algunas de estas son: Justo Daract (2004), Bingo-Teatro, Pedazos de labios en las tazas (2005), La Humedad de tu cuerpo (2007), Hazme una flor (2010), Villa Presunción I, II y III (2010-2012), Lo que viene con la noche (2012), El amor se olvidó el perfume (2012), He sido abducido/a (2011), Chico Folk (2012), Naturaleza Dogma (2012), Big Hamlet (2012), Verano en Tennessee (2017). Además, comparte la autoría y la dirección de la obra Época Puta (2010) con Alejandro Zingman y de La Verdadera Historia de la Aparecida Embarazada (2002) con Javier Vivas. Durante el año 2007 dirige el elenco de la Facultad de Ingeniería y Ciencias Económico-Sociales (FICES) de la Universidad Nacional de San Luis, y entre los años 2014 y 2015 tiene a su cargo la Comedia Municipal de Catamarca.

Sus creaciones fueron premiadas en varias oportunidades: La verdadera historia de la aparecida embarazada fue ganadora de la Fiesta Provincial de Teatro Teatrina 2002 en San Luis, ganadora de la III Fiesta regional del nuevo cuyo, La Rioja 2002 y seleccionada para representar a San Luís en la Fiesta Nacional de Teatro, Mendoza 2003; La humedad de tu cuerpo fue seleccionada para representar a San Luis en la Fiesta Nacional del Teatro 2009; Hazme una flor representó a San Luis en la Fiesta Regional del Teatro 2011 y Verano en Tennessee fue seleccionada para participar de la Fiesta Nacional de Teatro, en Rosario, año 2018. En cuanto a su poética podemos afirmar que Luis Palacio corresponde a la generación de teatristas dentro del canon de la multiplicidad del teatro de postdictadura según lo define Jorge Dubatti (2011):

Es el teatro en el canon de multiplicidad, donde paradójicamente lo común es la voluntad de construcción de micropoéticas y micropolíticas (discursos y prácticas al margen de los grandes discursos de representación) enfrentadas al capitalismo hegemónico y a las macropolíticas partidistas. El teatro se configura, así como el espacio de fundación de territorios de subjetividad alternativa, espacios de resistencia, resiliencia y transformación, sustentados en el deseo y la posibilidad permanente de cambio (2011:74).

Algunos lineamientos de la Poética de Luis Palacio son:

- En la elaboración de la mayoría de sus trabajos realiza una aproximación escrita, de gabinete, que luego será modificada y actualizada de acuerdo con la escena y el encuentro con los actores.

- La creación total del texto se sustenta en los aportes que recibe del cuerpo y las subjetividades de los actores y la escena a partir de las improvisaciones.

- Hay una preocupación por desarrollar temas de su lugar de origen, la ciudad de Villa Mercedes en la provincia de San Luis y en relación con otras provincias de Argentina.

- El tratamiento simbólico de los temas que desarrolla tiene una gran carga de ironía, erotismo y humor negro.

- En cuanto a su concepción estética emplea una variedad de improntas de actuación y puesta en escena: grotesco, realismo, performance, antropología teatral, entre otras.

- Hay siempre una preocupación en el espacio escénico y una búsqueda constante en romper el espacio convencional, teniendo en cuenta su efecto desde lo simbólico.

Para la identificación y análisis de algunos procedimientos autorreferenciales resonantes seleccionamos un grupo de obras en las cuales Palacio cumple múltiples roles participando como autor, director y actor. Estas obras son: Justo Daract (2004), Bingo-Teatro, Pedazos de labios en las tazas (2005), Villa Presunción I, II y III (2010-2012), Chico Folk (2012) y Verano en Tennessee (2017). 


\section{Presupuestos teóricos}

Para determinar algunos procedimientos autorreferenciales en la escena, en primera instancia reflexionaremos sobre la construcción de determinados presupuestos estudiados anteriormente y expresados en la bibliografía citada $y$, posteriormente, nos referiremos a algunos ejemplos observados en las obras de Palacio.

Para la construcción de estos presupuestos y preguntas se tomarán algunas conclusiones de lo realizado en la investigación de nuestra tesis doctoral denominada Dinámica de las poéticas teatrales en el acontecimiento escénico producido por el dramaturgo, actor y director Luis Palacio de Villa Mercedes (San Luis) (2018) y lo investigado en los proyectos Teatro, poesía y formas dramatúrgicas que descentran y traducen la política y el pensamiento (2014-2015) y Configuraciones escénicas del retrato en dramaturgias argentinas actuales (2016-2017) ambos de la Universidad Nacional de Córdoba.

El tema en cuestión nos lleva a realizarnos las siguientes preguntas: ¿Qué es la autorreferencialidad en las propuestas escénicas? ¿Autorreferencialidad es lo mismo que metaficción?, ¿es lo mismo que, en el caso de lo teatral, el metateatro? ¿Cómo se pueden explicar aquellos procedimientos autorreferenciales para identificarlos y analizarlos?.

Catherine Larson (1989) cita a Lionel Abel (1963) quien acuña el término metateatro en su estudio Metatheatre: $A$ New View of Dramatic Form definiéndolo como:

... piezas sobre la vida ya teatralizadas... Los personajes no están en escena sólo porque el dramaturgo los capturó en posturas dramáticas (como se hace con una cámara), sino porque ellos mismos sabían que eran dramáticos mucho antes de que el dramaturgo les prestara atención (Larson 1989: 1014).

Proponiendo que Abel se concentró en describir una nueva forma dramática sin detenerse en las diversas maneras que se presenta el metateatro ni los diferentes efectos en la escena. Luego Larson profundiza en las técnicas fundamentales del metateatro, tales como el drama dentro del drama y la idea de desempeñar un papel dentro de otro. A partir de aquí comienza a enfatizar en las características que debería tener el metateatro. La autora propone analizar al metateatro como una herramienta interpretativa que subraya la tensión que existe entre el arte y la realidad presentando cinco tipos de técnicas y utilizando el calificativo de drama autoconsciente:

1. El drama dentro del drama.

2. La ceremonia dentro del drama.

3. La idea de desempeñar un papel dentro de otro.

4. Las referencias o alusiones literarias o de la vida real. 5. La autorreferencia (Larson 1989: 1015).

Alfredo Hermenegildo, Javier Rubiera y Ricardo Serrano (2011) concuerdan que:

...propiciado por la apertura o indefinición del término acuñado por Abel, se ha producido una deriva terminológica que en su extremo permitiría reconocer como metateatral todo elemento que en un drama o en un espectáculo dados indica o hace recordar el carácter teatral de la ficción (2011: 12).

Los autores proponen que el germen metateatral se encuentra donde se rompe la ilusión de la ficción y la escena se presente desnuda, sin ningún artificio representativo, donde la aparición de lo real en forma de realidad se dé sin filtros.

Ahora bien, nos preguntamos qué relación existiría entre metateatralidad y autorreferncialidad. En este sentido podemos citar algunas definiciones que realiza Patrice Pavis (2016) en su Diccionario de la Performance y del Teatro Contemporáneo observando que toma como sinónimos "autorreflexibilidad" y "autorreferencialidad" colocando en la lista alfabética el término autorreflexibilidad y luego en su definición entre paréntesis explica: "autorreferenciales, se dice también".

Cuando un texto, dramático o de otro tipo, cuando una puesta en escena o una performance hacen referencia a sí mismas, son autorreflexivas (autorreferenciales, se dice también). Esta referencia puede tener que ver con la ficción de la obra (en cuyo caso se habla de metaficción), con su construcción (y deconstrucción), o con su temática (alusión, teatro dentro del teatro) (2016: 48).

Haciendo clara referencia a procedimientos metaficcionales, metateatrales o metaperfomáticos donde la ficción, el teatro o la performance hablan de su propia temática o propio procedimiento de construcción. Entendemos desde este párrafo que la autorreferencialidad es un concepto donde hay referencia en la obra hacia la escena estrictamente. La mirada se vuelve hacia el teatro mismo o la misma performance, hablaría entonces de procedimientos que hacen al convivio específico como toda acción escénica que se lleva a cabo dentro de una representación dramática que la contiene y en simultáneo en el mismo convivio. Anteriormente Pavis (2015) en su Diccionario del Teatro define a metateatro como: "Teatro cuya problemática está centrada en el teatro y que, por tanto habla de sí mismo, se “autorrepresenta”' (2015: 288).

Ahora bien, más adelante, el autor, propone otro efecto autorreflexivo:

Para la fenomenología, el "cuerpo vivo del actor es capaz de volver hacia sí la mirada del espectador", lo que será interpretado como un caso de autorreflexividad de la mirada del espectador. [...], el cuerpo remite a sí mismo, es un signo que remite la mirada hacia él antes de significar el mundo. Esto debería instarnos a prestar atención al fenómeno de la autorreflexividad (2016: 48).

En este sentido podría decirse que habría con el cuerpo un juego de espejo, es decir un juego donde existiría una identificación del espectador con el cuerpo del actor, esto sería claramente la consecuencia en la formación del registro imaginario a partir del proceso que el niño produce en su desarrollo con lo que Jacques Lacan (2002) denomina el estadío del espejo. El infans reconoce su imagen en el espejo y a partir de lo lúdico experimenta con sus gestos, de tal 
manera que produce un dinamismo libidinal, construyendo una estructura ontológica que promueve la identificación, es decir la transformación producida en el sujeto cuando asume su imagen. Este proceso sitúa la instancia del yo $(j e)^{1}$ construyéndose la matriz simbólica desde su forma primordial antes de objetivarse en la dialéctica de la identificación con el otro y antes de que el lenguaje le restituya en lo universal su función de sujeto (Lacan 2002: 86-87). Este caso particular, y primero en la función del imago ${ }^{2}$, establece la primera relación del sujeto con el otro, marca la percepción en las relaciones sociales. De esta manera el acontecimiento denominado estadío del espejo inaugura, por la identificación con la imago del semejante, la dialéctica que desde entonces liga al yo [je] especular con situaciones socialmente elaboradas. Podemos decir entonces que toda situación escénica de cuerpos presentes y en convivio produce este efecto de autorreflexibilidad donde la observación del cuerpo del otro hace volver hacia sí la mirada del espectador, como en toda relación social. Si bien en el teatro la experiencia espectatorial no determina la personalidad es interesante pensar en la remisión a sí mismo del cuerpo del otro que se produce en la identificación al presenciar el convivio. Ya en el siglo IV aC Aristóteles (1966) explica este proceso como "incidentes que excitan piedad y temor, mediante los cuales realizan la catarsis de tales emociones" (1966: 11), se podría interpretar entonces que procedimientos autorreflexivos se producirían en el cuerpo a partir de una identificación inconsciente con el otro.

En cuanto a los procedimientos denominados autoficción ${ }^{3}$, Pavis (2016) es muy claro en el posicionamiento que toma en el teatro como concepto trasladado de la literatura:

El autor habla de hechos personales reales, no inventados, pero totalmente recompuestos, con otra cronología, considerada imposible, pues necesita de la ficción para existir. [...] La autoficción teatral es más rara pero no inédita. Utilizaría los medios de la dramatización, la transposición y la recuperación de acontecimientos autobiográficos del autor, y reconstituiría en acciones escénicas estos elementos, tal cual ocurrieron (2016: 44)

Sergio Blanco (2016) realiza un recorrido histórico de los procedimientos autoficcionales finalizándolo con el descubrimiento freudiano del inconsciente en el siglo XX

El moi, tiene que ver con Yo en el sentido de cómo uno se percibe sí mismo, ligado a la conciencia, a lo que uno se percata, mientras que el je Lacan lo utiliza- para dar cuenta de la posición simbólica del sujeto (Ritsch, 2006),

2 Imago significa imagen en latín y es un término que ya había sido utilizado por el cristianismo en la expresión imago Dei. Pero llamó particularmente la atención de Jung a partir de la novela Imago de Carl Spiteller de 1906, una obra cuya trama está tejida entre la fantasía y la realidad de los personajes. A raíz del interés por este fenómeno y el término, se da este nombre a una de las primeras revistas de psicoanálisis, fundada por Hanns Sachs, Otto Rank y Freud mismo. La revista Imago se funda en 1912 con el propósito de articular el psicoanálisis con otras disciplinas tales como la antropología, la filosofía, la teología o la literatura (Murillo, 2014:123).

El término autoficción es mencionado por primera vez por Serge Doubrovsky, "en 1970 lo utiliza por primera vez en uno de sus manuscritos borradores llamado Le Monstre que más tarde, en 1977, se transformará en su célebre novela Fils. En una escena que pasa en el automóvil del narrado luego de su sesión de psicoanálisis, este piensa que a partir de sus sueños podría escribir una ficción y que podría hacerlo allí mismo al volante de su auto, y entonces dice: «Si escribo en mi automóvil mi autobiografía será mi AUTO-FICCIÓN»" (Blanco, 2016). y su exploración con el psicoanálisis a partir de lo cual se desacredita la autobiografía para habilitar la autoficción. De esta manera somos conscientes que al querer relatar nuestras propias vidas estamos construyendo otra vida, estamos creando un ente con pensamiento autárquico en el caso de la construcción escénica. Por lo tanto, podríamos decir que todos nuestros recuerdos son autoficcionales ya que se recrea constantemente desde la memoria otro yo, un yo ficcionado y cuando se lo transcribe en la escena es un yo poético.

Pavis (2016) propone otro procedimiento autorreferencial que es el performer que actúa su propia vida para los espectadores y lo denomina "autoperformer", en referencia a la palabra "autoficción", luego de definir este procedimiento propone el siguiente título "De la autoficción a la autoperformance" (2016: 44) y define al performer de la siguiente manera: "el performer actúa su propia vida para los espectadores" y además propone:

El performer, entonces, continúa siendo, o más bien siempre vuelve un poco a ser actor, autor y narrador. Vuelve a ser actor al mismo tiempo que trata de borrar las pistas escénicas para hacer creer que sólo se representa a sí mismo (2016: 45)

Exponiendo al sujeto performer siempre con la necesidad de producir autoficción porque "no permanece mucho tiempo como performer" (2016: 45) y luego citando a Lacan propone que "se pone en duda la integridad del sujeto" (2016: 45) y proclama al final de este título que, a partir de la noción de experiencialidad propuesta por la posnarratología, “... ni el sujeto, ni el actor, ni el espectador pueden comprender lo que es vivido, significado y recibido en la obra autoficcional sin hacer referencia a su propia experiencia concreta" (2016: 45). Poniendo en duda los límites entre realidad y ficción, esto supone que siempre hay algo de realidad en la actuación y algo de actuación en la realidad que se puede mostrar en escena. Pero no quedándose acá, Pavis muestra más adelante la utilización de procedimientos performáticos en distintos espectáculos anunciando también una evolución en la escena hacia formas más reales uniendo procedimientos narrativos complejos con la organicidad, lo real que propone la performance, en este sentido Pavis menciona expresiones como el body art, el live art y One-to-One performance (2016: 46).

En este sentido va nuestra investigación de la escena propuesta por Luis Palacio y su autorreferencialidad planteando además que el cuerpo del actor/performer "no es un mero emisor de signos, un semáforo ajustado con la idea de lanzar señales dirigidas al espectador; produce efectos en el espectador, ya los llamemos energía, vectores del deseo, flujo pulsional, intensidad o ritmo (Pavis, 2000: 79). Además producimos este análisis desde lo que Pavis denomina "vectores deseantes" que profundizamos en relación al deseo en el psicoanálisis y la estructura y función de los significantes desde el estructuralismo y post estructuralismo.

El tejido de materiales textuales y escénicos constituyen una red de significantes que se encuentran a la espera de significados posibles, y que, al mismo tiempo provienen de significantes primordiales, desconocidos, que poseen los intérpretes y/o los autores y directores y que son, sin 
dudas, productores de signos y efectos autorreferenciales en la medida que es la expresión de su propia concepción de mundo, de vida, de arte entretejida durante su constitución como sujeto. De tal forma que el sujeto creador, mediante recursos poéticos, construye una ficción contaminada con sus propias concepciones.

Podemos enunciar entonces que los procedimientos escénicos y textuales son construidos por un sujeto deseante cuyo cuerpo genera en el espacio y en convivio materiales concretos que siempre contienen direcciones inconsciente o consciente hacia alguna afectación.

Realizamos además un proceso de redefinición del objeto/problema de los estudios teatrales regionales articulándolos con sus matrices territoriales y culturales particulares, entendiendo al fenómeno teatral como un ente estético vivo. "Desde esta visión, las teatralidades y sus reflexiones contienen tensiones históricas con agenciamientos locales específicos, evidenciados en las condiciones del acontecer simbólico e imaginario, con funciones políticas e identitarias disímiles que requieren un abordaje casuístico" (Tossi, 2011: 32). El teatro en Argentina se presenta desde una dimensión político-identitaria, con resurgimiento en la postdictadura, que configura algunas pujas por la apropiación de sentidos que se posicionan en el campo social con determinados conocimientos y saberes regionales que cuestionan determinadas perspectivas hegemónicas en cuanto a estructuras y temáticas textuales y escénicas. Por ende las matrices regionales se encuentran cargadas de una amplia impronta territorial dinámica que empapa las producciones artísticas desde diferentes posicionamientos estéticos, éticos y políticos.

En este sentido tomamos los conceptos de territorialización, desterritorialización y reterritorialización en los procedimientos de autrorreferencialidad considerándolos en sus contextos geográficos-históricos-culturales singulares. Los conceptos de territorialidad y desterritorialidad son considerados como un tejido de segmentaciones. Es así que el análisis de los significantes autorreferenciales, en relación con la territorialidad, se ve comprometido en función de su resonancia a configurar diferentes mesetas rizomáticas y se diluyen, como parte de los corrimientos habituales en los sucesos de la cultura y política viviente.

Tomando las investigaciones de Gilles Deleuze y Felix Guattari (2006) podemos inferir que existe una segmentaridad "dura" que depende de grandes máquinas de binarización, una organización dual de los segmentos en círculos concéntricos y además existe una segmentaridad rizomática, que permite establecer un mapeo de los significantes en relación a su interpretación de forma flexible con círculos no concéntricos. La coexistencia de todas estas segmentaridades se encuentran trazadas, surcadas por líneas de fuga que proponen descodificaciones y recodificaciones, territorializaciones y desterritorializaciones. Como si constantemente una línea de fuga, incluso si comienza por un minúsculo arroyo, fluyese entre los segmentos y escapase a su centralización y eludiese su totalización (Deleuze y Guattari, 2006: 220).

De esta manera los procedimientos visuales o textuales elegidos en cada ente poético teatral son micro decisiones significantes que pueden instalarse en segmentos duros -territorialidades instituidas-, segmentos flexibles -no binarias, de multiplicidades de $\mathrm{n}$ direcciones-, o líneas de flujo mutante que tienden a escaparse de los códigos. El flujo mutante, convulsivo y creador se encuentra ligado al deseo libertario y modificador, en cambio las líneas duras y flexibles de segmentaridad son estables, siempre relacionados a significantes transparentes y codificados. Es desde aquí que los procedimientos reconocidos como autorreferenciales, ya sean que remiten al sujeto creador/a o a la construcción de la escena y el texto como meta lenguaje, se pueden considerar, a partir de la estructura, el trabajo y la concepción de mundo, como posibles segmentaciones que corresponden a diferentes procedimientos autorreferenciales que se territorializan, desterritorializan y reterritorializan. 
METATEATRALIDAD Y AUTORREFERENCIALIDAD EN LA OBRA de Palacio:

La metateatralidad en las obras de Palacio la interpretamos desde aquellos significantes que poseen una intensidad de significación haciendo referencia al discurso teatral propiamente dicho, y luego observamos los movimientos que se corresponden con los significantes relacionados con la autorreferencialidad produciendo líneas de fuga hacia la desterritorialización que permiten definiciones y cuestionamiento de la actividad teatral. Los significantes metateatrales son parte de la meseta que corresponde a la línea dura que hace referencia a la sobrecodificación, círculos concéntricos con gran resonancia. Los demás significantes se interpretaron de la siguiente manera: algunos a partir de las líneas flexibles, como segmentaciones primitivas, y otros como procesos de líneas de fugas que proponen desterritorializaciones y descodificaciones. Ambos grupos se analizaron en referencia a significantes que proponen significaciones relacionadas con la autoficción y autorrerencialidad.

En los diferentes análisis de casos, interpretamos los significantes que proyectan una significación determinada, a partir de la actividad deseante en su encuentro con el Otro , con los desfiladeros del significante particulares del sujeto creador. El sujeto marcado por estos significantes en su proceso identitario construye un deseo que le es propio, de esta manera observamos lo que Palacio reflexiona sobre el teatro.

La obra Justo Daract (Palasi, 2018:199-223) relata las peripecias de dos muchachos que intentan, mediante la canción, tener éxito e irse de su pueblo con consecuencias diferentes para cada uno y un final trágico. Fue estrenada en Villa Mercedes en el año 2003 y en 2018 reestrenada en Merlo con otro elenco. En esta producción es muy clara la referencia metateatral del significante 'máquina de hacer historias', frase expresada en el comienzo de la obra por el personaje Nelly, a modo de explicación de lo que el público va a ver. Esta metáfora de la actividad discursiva del teatro es, sin dudas, una referencia directa de lo que piensa el autor sobre el teatro. En este caso, los significantes flexibles relacionados con la autorreferencialidad son los significantes 'formación', 'suerte', 'éxito’ y 'deseo' que los situamos en estas mesetas primitivas con cierta movilidad, fundamentalmente a partir de las líneas de fuga que producen los significantes 'quiero ser' y 'muerte'. En Justo Daract, en esta 'máquina de hacer historias' que se da en el contexto de un pueblo, con características similares al lugar del autor y marcado por la 'muerte' del ferrocarril, presenciamos la relación de los personajes -que el autor relaciona en la entrevista (Palasi, 2018:319) con una etapa de su vida- envueltos en conflictos de 'formación', 'suerte', ‘éxito' y 'deseos' que son resignificados, recodificados permanentemente por el 'quiero ser'. Estos significantes poseen un peso en su intensidad para el autor de la obra, debido a que, durante esos años, su deseo de formación y búsqueda de su impronta en el arte, específicamente en la actividad teatral, se transformó en una marca de su vida profesional. Viviendo en Buenos Aires participaba de castings y obras teatrales que le permitieron conseguir experiencia en el medio y una forma de pensar y hacer en la escena. La 'máquina de hacer historias' era el lugar donde poder proyectarse más allá de su lugar de origen. La cade- na de significantes en sus vectorizaciones durante la obra se conecta, metonímicamente, en ese sentido, con un contenido irónico que le permite a Palacio reírse de sí mismo.

En Bingo Teatro-Pedazos de labios en las tazas (Palasi, 2018:225-247), escrita en 2007, durante el juego de un bingo, Perpetua, la poetisa con un destino inevitablemente trágico, el de cumplir con el mandato de su padre, Banina, la artista plástica, buscando su realización personal y el sentido del arte y Daniela, la bolillera, una exprostituta que ama y sufre intentan, en el final de sus vidas, explicar el sentido del arte. En esta obra la metateatralidad se relaciona, fundamentalmente, con el significante 'arte'. Podemos hablar de dos significantes primordiales que se configuran como grandes centros: 'arte realista' y 'arte surrealista', estos son los núcleos esenciales de la obra, como si esta estuviera hecha para hablar del arte y sus posibilidades transformadoras. En base a un relato, entre surrealista y absurdo, Palacio propone que reflexionemos sobre el arte. Si bien no es metateatral exactamente, podríamos decir que es meta-artístico. En las mesetas flexibles podemos hablar de significantes como 'dictadura del arte' o 'la muerte de los saberes preconcebidos' para emprender una nueva experiencia artística. Lo que propone la desterritorialización como significante con sentido desestabilizador, es el 'juego', que brinda una clara orientación hacia un sector de la población al que no le interesan estas discusiones con el doble sentido de distraer y de incluirlas en la discusión sobre la finalidad del arte.

La obra Villa Presunción (Palasi, 2018:257-289), realizada en tres capítulos, fue estrenada entre 2010 y 2011 y su relato se basa fundamentalmente en el proceso de investigación que lleva adelante un grupo de científicos en un pueblo sobre algunos hechos sorprendentes que se suceden relacionados con su historia. Esta obra lleva en su título el significante que proporciona la base de las técnicas actorales: 'presunción'. No hay certezas, sólo presunciones de cómo debería ser o sentir tal o cual personaje, la 'presunción' es un significante metateatral que otorga todo el sentido a la obra en relación a las dudas en la construcción del relato, a los supuestos que es necesario verificar permanentemente en la historia. De hecho, las técnicas de investigación de los protagonistas para averiguar la verdad son técnicas teatrales:

Charo: Nosotros con un sistema de avanzadas técnicas teatrales podemos ponernos en la piel de los personajes a investigar. Con esta capa me convierto en Rosa Camargo (Palasi, 2018:174).

Lo metateatral, en relación con el deseo del Otro que subyace en esta obra, como lo instituido, se refiere fundamentalmente a una forma de creación de los personajes, a "ponerse en la piel de los personajes", al "como sí" stanislavskiano que unido a 'presunción' está haciendo referencia a posibles técnicas utilizadas. Por otro lado, podemos mencionar la posición del yo frente al otro en relación al fantasma, para la reacomodación del deseo propio en función del deseo del Otro, esto es la posibilidad de la conexión en la actuación con el otro ficcionado, como experiencia especular con la imagen del otro como fundante del arquetipo del yo, resolviendo su desamparo. Por este motivo, podemos concluir que la obra presenta una autorreferencialidad vinculada con el deseo del autor puesto en 
la actuación, al crear personajes que se 'ponen en la piel' de quienes van a investigar dentro de las incógnitas de Villa Presunción. La línea de fuga y desterritorialización, que se presentan como una vectorización del deseo secante, es la puesta en escena del segundo capítulo con búsquedas de técnicas relacionadas con la 'performance'. El relato, en el capítulo 2 de la saga, sigue siendo el mismo y a nivel discursivo la 'presunción' es el tema, pero a nivel energético en la actuación es el cuerpo que acciona políticamente, desde sensaciones genuinas, permitiendo una discontinuidad con la propuesta de 'ponerse en la piel de otro'.

Esta contraposición de miradas de lo teatral comienza a observarse más claramente en la puesta en escena de Chico Folk (Palasi, 2018:291-299), propuesta escénica unipersonal estrenada en Villa Mercedes en el año 2012 que nos relata, de forma fragmentada, el recorrido emocional y físico de un muchacho de pueblo en su proceso de elección de género. En esta obra representación y presentación compiten y se complementan. Lo instituido como línea dura en la segmentación es fundamentalmente el unipersonal donde, en la actuación, hay marcas reconocibles de búsquedas de representación desde la antropología teatral que permite un nuevo lenguaje codificado en cuanto a la utilización del cuerpo y de los objetos. Por otro lado, las líneas que llamamos primitivas son en relación a lo autorreferencial y tienen que ver con la elección de los objetos, fundamentalmente los casetes y la pollera -con referencias directas a su historia personal en el caso de los casetes y con referencia a lo cuyano en el caso de la pollera-. Pero, por otro lado, intervienen resonancias que producen desterritorialización en el momento en que el cuerpo del actor-autor Palacio deja de ser representacional para convertirse en presentacional demostrando en este caso cómo las investigaciones sobre performance se desarrollan, en cierto momento, donde lo que se produce son energías reales, sensibles desde el estar ahí sin ningún tipo de superficialidad actoral.

El teatro como parte del relato, a modo de búsqueda del conocimiento del yo, Palacio lo trabaja concretamente en Verano en Tennessee (Palasi, 2018:301-315), estrenada en 2017, donde el argumento se desarrolla alrededor de un grupo de personas que se reúnen para hacer terapia y su metodología es similar al psicodrama, con la diferencia de que emplean los temas y conflictos planteados en las obras de Tennessee Williams, especialmente en Háblame como la lluvia y déjame escuchar, Súbitamente el último verano y en El Zoo de Cristal. Las improvisaciones con funcionalidad terapéutica se transforman en el significante inicial y constitutivo de la obra para desarrollar el proceso de identidad de los personajes, e ir develando la trama que los pondrá en conflicto. Este significante es un procedimiento en sí mismo que los relaciona con su propio fantasma, a partir del cruce de cada personaje con el Otro, configurando sus deseos. La forma de trabajo en la preparación de la obra se centró en la búsqueda de sentimientos genuinos, se corresponde con la autorreferencialidad de cada uno de los actores en la creación colectiva, ya que en los ensayos llevaron su cuerpo al límite de sus resistencias, utilizando técnicas a partir del estudio de la performance. Sánchez Harriet explica, en este sentido, que para los ensayos cada uno llevaba sus problemáticas personales para ponerlas en juego, según lo interpretado de los conflictos que propone Williams en sus obras (Palasi, 2018:387). Así, esta metodología de trabajo para la creación de Verano en Tennessee va produciendo líneas de fuga que compromete la estabilidad del sentido inicial en la vectorización propuesta del teatro dentro del teatro permitiendo, hacia el final de la obra, la confusión de realidad y ficción. 


\section{CONCLUSIón}

Las lecturas de los significantes de las obras de Luis Palacio a partir de la intersección entre la herramienta de los vectores deseantes propuestos por Patrice Pavis (2000) y teorías psicoanalíticas, relacionadas con lo simbólico y su relación con el deseo, nos permitieron configurar una macropoética de Palacio que en este trabajo, lo refererimos sólo a los procedimientos autorreferenciales.

Hemos investigado, topológicamente cada obra para construir, por un lado, una micropoética a partir de los significantes que resuenan en el cuerpo, tanto de los creadores como de la investigación y, por otro lado, el análisis de las obras, en su conjunto, permite definir una macropoética que se corresponde con el proceso de creación visto desde la diacronía del movimiento creativo.

Uno de nuestros objetivos fue distinguir, a partir del dispositivo de los vectores, en relación con procedimientos de autorreferencialidad, los significantes más resonantes, la actividad deseante de Palacio como creador e impulsor de creaciones teatrales y analizar, además, algún tipo de significante que fuera el conductor, al modo de semblante, que corta la cadena de significantes, una falta que expresa lo ininterpretable, la hiancia que nos compromete como sujetos del inconsciente. Logramos, de esta manera, establecer, en cada una de las micropoéticas analizadas, algunos significantes resonantes que conmueven la creación. Estos significantes resonantes están conectados, generando características específicas de la poética de Palacio.

Desde este procedimiento investigativo podemos afirmar que Palacio, mediante todas las referencias metateatrales que realiza en las obras analizadas -desde sus significantes textuales o sus procedimientos de creación- pone sobre el tapete, permanentemente, su ubicación personal dentro del teatro y su cuestionamiento de la funcionalidad del arte, en general, y el teatro, en particular. 


\section{Biblografía}

ARIStóteles (1966). Poética. España: Editorial Aguilar.

ABEL, L. (1963) Metatheatre: A New View of Dramatic Form. New York, Hill and Wang,

BLANCO, S. (2016). La autoficción: una ingeniería del yo. 01/03/2021, Revista Temporales Sitio web: https://wp.nyu.edu/gsas-revistatemporales/la-autoficcion-unaingenieria-del-yo/-

Dubattı, J. (2010) Herramientas de Poética Teatral: concepciones de teatro y bases epistemológicas. Revista Texturas, 9/10 (9), 341-352. doi: https://doi.org/10.14409/texturas.v1ig/10.2891.

_- (2011). El teatro argentino en la Postdictadura (1983-2010): época de oro, destotalización y subjetividad. Stichomythia, 11-12, 71-80. Recuperado de http://parnaseo.uv.es/Ars/stichomythia/stichomythia11-12/indice.html (1/05/2018).

LACAN, J. (2002). Escritos. Buenos Aires: Siglo XXI, Editores Argentina: Buenos Aires.

__(2007) Seminario 2: El yo en la teoría de Freud y en la técnica psicoanalítica. Buenos Aires: Paidos.

Murillo, M. (2014). El significante no es un arquetipo. Anuario de Investigaciones. Universidad de Buenos Aires, Vol. XXI, 119-126. http://www.redalyc.org/articulo. oa?id=369139994055-

Palasí, M. A. (2018) Dinámica de las poéticas teatrales en el acontecimiento escénico producido por el dramaturgo, actor y director Luis Palacio de Villa Mercedes (San Luis). Córdoba: Mapa, repositorio digitar de la Facultad de Artes, UNC.

__ (22/07/2015). Lauwers, Jan, Sad Face/Happy Face, una trilogía sobre la humanidad. Dramaturgia que provoca. RECIAL-Revista del CIFFYH Área Letras, Vol. 6 Num. 7, https://revistas.unc.edu.ar/index.php/recial/article/view/11910.

Pavis, P. (2000). El análisis de los espectáculos. Teatro, mimo, danza, cine. Barcelona: Paidos.

__(2015). Diccionario del Teatro. Dramaturgia, estética, semiología. Buenos Aires: Paidos.

_(2016). Diccionario de la Performance y del Teatro Contemporáneo. México: Toma, Ediciones y Producciones escénicas y cinematográficas, A. C.

Ritsch, G. (2006). Algunas consideraciones acerca del sujeto y el yo. 08/03/2021, de El Sigma.com Sitio web: https://www.elsigma.com/introduccion-al-psicoanalisis/ algunas-consideraciones-acerca-del-sujeto-y-el-yo/10010.

TRAStoY, B. (2009) Miradas críticas sobre el teatro posdramático. AISTHESIS № 46 (2009): 236-251 • ISSN 0558-3939. Chile: Instituto de Estética - Pontifi cia Universidad Católica de Chile.

Tossı, M. (2011). Poéticas y formaciones teatrales en el noroeste argentino: Tucumán 19541976. Buenos Aires: Dunken.

LARSON, C. (1989) El metateatro, la comedia y la crítica: Hacia una nueva interpretación. AlH. Actas X. Buenos Aires: Centro Virtual Cervantes. 1013-1019.

Hermenegildo, A., Rubiera, J. Serrano, R. (2011) Mas allá de la ficción teatral: el metateatro. Revista sobre el teatro áureo. № 5. Canadá: Teatro de los siglos de oro. 9-16. 